\title{
MANUFACTURER'S COOPERATION STRATEGY OF CLOSED-LOOP SUPPLY CHAIN CONSIDERING CORPORATE SOCIAL RESPONSIBILITY
}

\author{
Yingluo Yan, Fengmin YaO* And Jiayi Sun
}

\begin{abstract}
Corporate social responsibility (CSR) has become a popular and important strategy for corporate operation and sustainable development. Meanwhile, many social or environmental incidents that occur in one enterprise could bring huge risk or disruption for the entire supply chain. This study discusses the manufacturer's cooperation strategy of closed-loop supply chain (CLSC) composed of a dominant manufacturer with CSR behavior consciousness, a retailer with CSR investment, and a third-party recycler. In the CSR-CLSC, the manufacturer exhibits CSR behavior consciousness through considering stakeholders welfare, the retailer makes CSR investment through profit donation and the third-party recycler exhibits CSR activity through product recycling. And under the Stackelberg Game setting, we formulate four different decision-making models to investigate the interaction between manufacturer's CSR behavior consciousness and retailer's CSR investment, as well as their impact on the manufacturer's cooperative strategy selection and CLSC operation. The results show that both the CSR behavior consciousness of manufacturer and CSR investment of retailer are conducive to reducing the wholesale price of new products, enhancing the recycling rate of waste products and improving the performance of CSR-CLSC members, and both of them have the function of mutual incentives. The vertical cooperation strategy of manufacturer is conducive to increasing the overall performance of CSR-CLSC, and compared with the cooperation with the third-party recycler, the manufacturer has stronger motivation to cooperate with the retailer, and it is also more beneficial to improving the CSR investment level, the waste product recycling rate, and the performance of CSR-CLSC members.
\end{abstract}

Mathematics Subject Classification. 91B06, 91A80.

Received May 28, 2021. Accepted November 9, 2021.

\section{INTRODUCTION}

With the continuous development of 5G, artificial intelligence and other technologies, the speed of product update iterations has gradually accelerated. The resulting large number of discarded products have also made environmental pollution and resource shortages more serious. Recycling and remanufacturing of waste products provide a good virtuous cycle for reducing environmental pollution and resource waste. Because recycling and remanufacturing can not only restore the waste products to the same quality and performance as the products using raw materials, but also effectively reduce energy consumption and air pollution $[5,53,56]$. For example, Apple reduces carbon emissions per dollar of revenue by $15.4 \%$ by recycling and remanufacturing. Many

Keywords. Closed-loop supply chain, CSR behavior consciousness, CSR investment, cooperative strategy.

School of Economics and Management, Harbin University of Science and Technology, Harbin 150080, P.R. China.

*Corresponding author: fengmin_yao@hrbust.edu.cn 
manufacturers such as Ford, IBM and Xerox have saved at least millions of dollars a year by recycling and remanufacturing $[7,12,52]$. By participating in the recycling and remanufacturing of waste products, enterprises not only obtain good economic benefits, but also effectively reduce raw material consumption, energy consumption and environmental impact. Therefore, many enterprises begin to balance economic and environmental benefits by implementing closed-loop supply chain (CLSC) management [13,19].

For consumers, with the progress of economy and society, motivations of purchasing a product include not only price and environmental responsibility, but also social responsibility [53]. Globally renowned brands such as Nike and Adidas are under pressure from consumer boycotts and reputation damage due to inhumane labor and business activities [3]. Therefore, an increasing number of companies not only realize the circulation of product flow through the CLSC management mode, but also start to incorporate the construction of social responsibility into the company's operation and management strategy [54,59].

Corporate social responsibility (CSR) can be regarded as a form of corporate self-regulation, which usually means that enterprises should pay attention to the impact on society and the environment in the production and operation process, and encourage enterprises to actively engage in social activities such as human rights protection, environmental protection (such as recycling of discarded products) and charitable donation $[20,41,43]$. CSR can not only help enterprises improve their relationship with stakeholders (including suppliers, customers, society and environment, etc.), but also reduce business risk and enhance enterprise value $[2,36]$. Therefore, more and more enterprises begin to pay attention to the construction of CSR, and begin to influence or even promote consumers' purchase decisions through CSR strategy [39,51]. At the same time, with the development trend of globalization, it is not enough for companies to focus on their own social responsibilities, but also pay attention to and control the social responsibilities of other companies in the supply chain, so the CSR has extended to the entire supply chain $[10,39]$. Apple is frequently blamed for the inhumane labor and business practices of its supplier Foxconn [33]. Incidents such as the Dow Corning Silicone Leakage Incident and the American Manville Asbestos Disease Incident also indicate that under the CSR environment in the supply chain, the irresponsible behavior of any node enterprise may cause difficulties in the operation of the entire supply chain [21]. Therefore, it is necessary and important to integrate CSR into CLSC to study the impact of CSR on business decisions.

Modern theory and empirical analysis show that nodal enterprises in the CLSC may freely and strategically choose to participate in social responsibility activities due to their different positions, so as to better fulfill CSR and improve corporate reputation $[16,43]$. In fact, studies have shown that the manufacturer, usually as the dominant player in the supply chain, can often obtain more channel profits. Therefore, the dominant manufacturer often implements CSR in a way that benefits stakeholders to achieve the goal of more stable operation of supply chain system. As the retailer is closer to consumers, they are more inclined to make CSR investment in the form of profit donations to directly stimulate consumption. For example, in 2009, MercedesBenz cooperated with Hainan United Crown Automobile Service to jointly organize the "charity Benz series of activities to subsidize the Shishan lonely elderly project", in which Mercedes-Benz made some concessions to the dealer's purchase, and the dealer directly donated some profits to the local public welfare organization (http: //auto.sohu.com/20110425/n306399855.shtml). In 2017, in the "I (love) public welfare" activity jointly held by Apple and Jingdong, Apple gave part of the profits to Jingdong's purchase and also gave consumers certain direct discounts (activity during explosion Apple product full 1000 minus 100), and Jingdong promises users every purchase during the activity of Apple products, its directly to the public welfare organization to donate 1 yuan love of money (http://www.techweb.com.cn/news/2017-04-26/2517388.shtml). However, when the member companies in the CLSC perform CSR in different forms, the interaction between the CSR behavior of the companies and the impact of the CSR behavior of the different member companies on the operation and performance of CLSC have not been studied.

In addition, in order to improve competitiveness and operational efficiency, manufacturers will adopt a strategy of cooperation with retailers or third-parties [25]. For example, Xiaomi strengthened its forward logistics by acquiring Yomi, a distributor in South Korea [46]. The three major US automakers (GM, Ford, Chrysler) and professional third-party recyclers have established long-term and stable cooperative relationships in order 
to carry out auto parts recycling [34,50]. Similarly, some manufacturers (such as Changhong, one of famous home appliances manufacturers in China) cooperate with downstream retailers (such as Suning, one of famous home appliances retailers in China) on the one hand, and integrate third-parties to strengthen the recycling and remanufacturing of used products on the other $[46,50]$. Currently, although some scholars have studied the choice of cooperation strategies of manufacturers in the supply chain, they have not extended it to the CLSC that considers CSR behavior. Existing research indicates that the impact of CSR on the cooperation between supply chain members is very meaningful [22]. However, studies of CLSC associated with CSR focus on pricing strategies and coordination, whereas the manufacturer's cooperation strategy of CSR-CLSC has rarely been quantitatively examined.

The purpose of this paper is to address the above-mentioned issues by merging five research streams: CSR, consumer surplus, profit donation, recycling and manufacturer cooperation. In this regard, this study considers the establishment of a CSR-CLSC that includes a dominant manufacturer with CSR behavior consciousness, a retailer with CSR investment, and a third-party recycler. While pursuing profits, the socially responsible manufacturer also pays attention to the welfare of their stakeholders through the profit giving behavior. The retailer makes CSR investment through profit donation. The recycler exhibits CSR activity through product recycling. As such, the profit function of the socially responsible manufacturer consists of pure profit that it earns by wholesale new products, profit due to remanufacturing of used products and effects of CSR through consumer surplus that it earns from the stakeholders. The CSR investment behavior of retailer through profit donation will potentially affect consumer demand. Specifically, this article attempts to address the following questions.

(1) What is the interaction between the manufacturer's CSR behavior and the retailer's CSR investment? How does the CSR behavior of different member enterprises affect the performance of CSR-CLSC members and overall?

(2) How does the CSR behavior of different member enterprises affect the recycling of used products and the pricing of new products?

(3) Can the manufacturer pursuing maximum social welfare encourage the retailer to make more profit donations and the third-party to try its best to recycle waste products?

(4) Should the manufacturer cooperate with retailer or recycler? How does the CSR behavior of each member enterprise affect the manufacturer's cooperation strategy and CSR-CLSC operation?

The rest of this paper is structured as follow. In Section 2, we present the literature review. The detail of problem (including assumptions and annotations describe) is described in Section 3. In Section 4, we provide mathematical models and solutions under different situation. Section 5 makes a comparative study of the equilibrium results under different decision-making models. We illustrate the numerical simulation in Section 6 , and finally in Section 7, conclusions and future research are suggested.

\section{LiterATURE REVIEW}

This paper involves three strands of research, namely CLSC operation, CSR and sustainable supply chain, and manufacturer's cooperation strategy.

\subsection{CLSC operation}

At present, many researches explore the optimal price decisions, recycling management and operation in CLSC from different aspects. For example, Savaskan et al. [45] earlier investigated the optimal pricing decision and recycling channel selection of CLSC under three different recycling modes (viz, the retailer, the manufacturer or the third-party collection). In extension to this study, Savaskan and Wassenhove [44], Chuang et al. [8], Wei et al. [56] separately studied the effects of retailer competition, recycling cost structure, recycling regulations and information symmetry on CLSC recycling channel selection and performance. Hong et al. [15] further investigated the impact of advertising effects on CLSC pricing and recycling decisions. Mondal and Giri [38] 
discussed the impact of green innovation and market efforts on waste product recycling and CLSC operations. Considering the government regulation, Zhang et al. [62,63] respectively studied the influence of government reward and punishment mechanisms and fund policies on CLSC decision-making and remanufacturing mode selection. Liu et al. [31] investigated the influence of deposit return system of government waste electronic and electrical products on recycling decision of CLSC and environment. Considering that consumers have different price perceptions of new products and remanufactured products, Ferrer and Swaminathan [11] studied the pricing decision of new and remanufactured products in two-stage and multi-stage CLSC. Consider the influence of channel power, Liu et al. [29] further studied the impact of different channel power structures on the pricing of new products and remanufactured products in a multi-cycle CLSC. Choi et al. [7] analyzed the impact of channel powers on CLSC performance and coordination based on the channel structure of the third party responsible for recycling. Hong and Yeh [14] pointed out that the channel recovery rate, manufacturer's profit and total channel profits when the retailer is responsible for recycling is not always better than that when the third-party is responsible for recycling. At the same time, due to the impact of factors such as economies of scale and fixed investment, the cost of recycling waste products by manufacturers or retailers is usually higher than that by the third-parties recyclers, and the third-party recycling mode is very important and common in current practice activities $[1,34]$.

Although the existing studies have investigated the recycling and pricing decisions of CLSC from the perspectives of government regulation, member's competition and channel power, which to some extent has laid a foundation for this study. However, the above literature does not study the impact of CSR behavior and profit donation activities on waste product recycling and CLSC operations. Therefore, based on the channel structure when the third-party recycling, this paper will analyze the impact of manufacturer's CSR behavior on the retailer's profit donation activities, the third-party's waste product recycling activities and CSR-CLSC operation.

\subsection{CSR and sustainable supply chain}

CSR combines corporate economic performance, environmental performance and social welfare practices, which is widely regarded as a highly relevant and effective for companies to contribute to sustainable development $[48,61]$. In recent years, some scholars have studied the influence of CSR on supply chain operation from different perspectives. The relevant research can be roughly divided into two categories: one is from the perspective of CSR behavior, which is regarded as an exogenous variable. It is believed that enterprises can achieve the goal of improving the interests of stakeholders by setting the goal of maximizing the social welfare considering consumer surplus. For example, Modak et al. [35] demonstrated the CSR behavior of manufacturer in the form of consumer surplus, and studied the impact of manufacturer's CSR attention on product competition, profit distribution and coordination in the dual channel supply chain. Panda et al. [42] studied the supply chain coordination of manufacturer with CSR behavior, and proposed a contract-bargaining process that included two wholesale price discount-Nash bargaining contracts to alleviate channel conflicts and distribute channel profits. Liu et al. [27] investigated the impact of CSR and cost-sharing contracts on supply chain operations and coordination for a supply chain system consisting of a retailer and multiple manufacturers. Panda et al. [43] further extended the model of manufacturers to show CSR behavior by focusing on consumer surplus into the research of CLSC, focusing on investigating the impact of manufacturer's CSR behavior on waste product recycling and CLSC operation. On this basis, Shu et al. [48] studied the influence of manufacturer's CSR behavior on enterprises' carbon emissions, waste product recycling and product pricing decisions. Modak et al. [37] further expanded the existing research model to study the impact of manufacturer's CSR behavior and retailer competition on CLSC decisions. Liu and Xiao [26] studied the CSR preferences of manufacturer and consumers and the impact of green consumers on CLSC reverse channel structure selection, new product pricing, and recovery ratios. Wang et al. [55] studied the interaction between manufacturer's CSR behavior and retailer's fairness concern behavior, as well as their impact on CLSC performance and government subsidy efficiency.

The other is from the perspective of CSR investment, and considers CSR behavior as an endogenous variable. It is believed that the CSR behavior refers to various activities in which enterprises invest a certain cost to 
improve the interests of stakeholders. For example, $\mathrm{Ni}$ and $\mathrm{Li}[40]$ analyzed the internal relationship between CSR investment behaviors of upstream and downstream enterprises in two-tier supply chains, and discussed the impact of CSR investment behaviors on supply chain performance. Wu et al. [58] studied the impact of CSR investment on supply chain decisions, and proposed two types of contracts that can improve supply chain performance. Ma et al. [33] expanded the existing research model based on information symmetry, and studied the supply chain coordination problem considering CSR investment under the condition of asymmetric cost information. Liu et al. [28] further investigated the impact of CSR cost information asymmetry on supply chain decisions. Aaya and Mittendorf [4] pointed out that companies can perform CSR by donating to the society, and investigated the impact of government subsidy policies on corporate donations and supply chain decisions. Modak et al. [36] investigated the impact of different recycling channel structures on corporate donation behavior and CLSC decision-making and coordination. Song et al. [49] expanded the existing research model and studied the impact of CSR investment on CLSC operations under government subsidies. Wu et al. [59] discussed the impact of manufacturer's environmental responsibility behavior on CLSC pricing and recycling decisions. Liu et al. [30] studied the impact of CSR input and price competition behavior among retailers on CLSC operation performance.

Although the existing literature has studied the impact of CSR on supply chain operations from various aspects, most of them have investigated the impact of CSR behavior of individual enterprise on supply chain operation, and have not discussed the mutual influence of different member enterprises' CSR behavior. At the same time, the existing literature does not study the interaction between CSR and manufacturer's strategic choices.

\subsection{Manufacturer's cooperation strategy}

In order to improve the efficiency of supply chain and enhance its competitiveness, the manufacturer as the leader of supply chain pays particular attention to the choice of cooperation strategy. In recent years, there have been a lot of literatures on the selection of manufacturer's cooperation strategies in supply chain. For example, Chen et al. [6] investigated the impact of competition or cooperation between manufacturer and remanufacturer on the remanufacturing of waste products. Li et al. [24] analyzed the impact of the cooperation between remanufacturer and retailer or recycler on the recycling of used products and the economic and social profits of supply chain. Jena and Sarmah [18] studied the impact of non-cooperation, partial cooperation and all cooperation on the recycling of used products and product pricing for a supply chain consisting of two manufacturers and one retailer. Zhou et al. [66] studied the advertising cooperation strategy and retailer ordering problems with risk avoidance for manufacturer and retailer. Li et al. [23] have expanded the existing research model of vertical cooperation and systematically analyzed the impact of horizontal and vertical cooperation on carbon reduction, waste product recycling and optimal decision-making in low-carbon CLSC. Xie [60] studied the effects of different cooperation strategies of competitive suppliers in a decentralized supply chain on product demand, energy efficiency and corporate profits. For the CLSC composed of a manufacturer, a retailer and two recyclers, Ma et al. [34] analyzed the impact of different cooperation models on CLSC pricing and recycling decisions. Wei et al. [57] further pointed out that when the competition intensity between recyclers is relatively intense, the manufacturer integrating the retailer and one recycler is more conducive to improve the recycling efficiency and profits of CLSC. Zheng et al. [65] expanded the existing research model by introducing corporate fair-concern behavior, and investigated the impact of retailer's fair-concern behavior on the cooperative strategy and the performance of CLSC. Zhang et al. [64] investigated the influence of retailer's vertical and horizontal fairness concern behavior on the optimal sales model of supply chain members. Liu et al. [32] studied the influence of retailer's fairness preference on the cooperative relationship of sustainable supply chain members. Shi et al. [47] constructed four alliance strategic models of CLSC considering the manufacturer's green effort and retailer's service effort, and investigated the impact of different alliance strategies on green input, service level and CLSC performance.

Although the existing research has investigated the factors that affect the cooperation of supply chain members and the impact of cooperation on supply chain performance from some aspects, the existing research has 


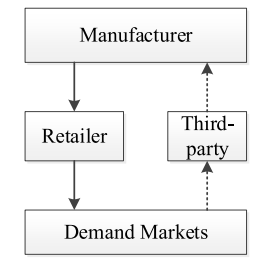

(a)

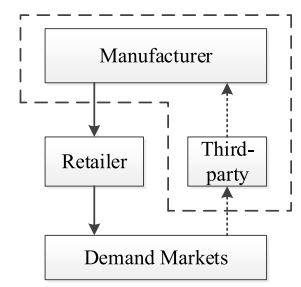

(c)

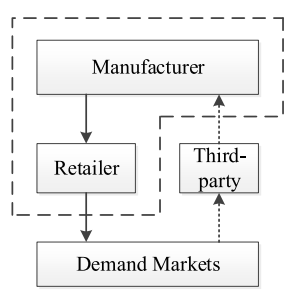

(b)

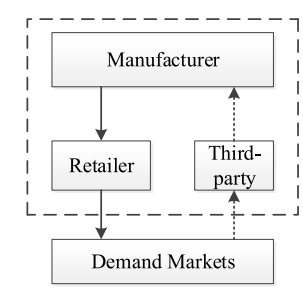

(d)

Figure 1. Cooperative models of CSR-CLSC. (a) Model N. (b) Model MR. (c) Model MT. (d) Model MRT.

not explored the impact of CSR on manufacturer's cooperation strategies in the context of CSR-CLSC. Based on this, this study further expands the existing research models and builds corresponding decision models to investigate the impact of different enterprises' CSR behavior on manufacturer's different cooperation strategies.

\section{PROBlem DESCRIPTION AND ASSUMPTIONS}

\subsection{Problem description}

We consider a CSR-CLSC consisting of a manufacturer, a retailer and a third-party recycler (referred to as the third-party), and the three players belong to Stackelberg Game with complete information and the manufacturer is the channel leader. In the forward supply chain, the manufacturer produces new products and distributes them to the retailer for sale. In the reverse supply chain, the third-party is responsible for recycling waste products and the manufacturer is responsible for remanufacturing waste products.

In the CSR-CLSC, as the channel leader, the manufacturer has CSR behavior consciousness that pays attention to her stakeholders [35]. It is assumed that according to the stakeholder theory, business operations should be accountable for all stakeholders in CSR enterprises, including governments, employees, suppliers, retailers and consumers. Consumers are the critical component of all stakeholders, and therefore, the manufacturer's CSR is reflected by consumer surplus, in line with the majority of studies [26, 43].

Meantime, in reality, donation is one of the core social responsibility activities involved in the social responsibility management system $[30,36]$. There are numerous instances on how donation is made by companies all over the world. For example, Wal-Mart donated US $\$ 311.6$ million to social and economic development, environmental protection and hunger. During the COVID-19 outbreak, Chinese companies such as Alibaba and Suning donated protest funds and materials to many countries around the world. These examples show how retail companies are using charitable donations as a core tool of CSR [30]. Based on this, in this paper, the retailer makes CSR investments by donating part of the profits from unit sales to social welfare organizations $[36,49]$.

In order to further investigate the impact of CSR on the selection of manufacturer's cooperation strategies in CLSC, we extended the research models of Jena et al. [18] and Shi et al. [46] to the background of CSR-CLSC, and constructed four different decision models as shown in Figure 1. The four CSR-CLSC decision models 
TABLE 1. Notation description.

\begin{tabular}{ll}
\hline \hline Notations & Description \\
\hline$w$ & The unit wholesale price of manufacturer \\
$c_{m}$ & The manufacturer's unit cost of production a new product, $w>c_{m}$ \\
$c_{r}$ & The manufacturer's unit cost of remanufacturing a used product, to ensure that the remanufacturing \\
& is economically feasible, $\Delta_{0}=c_{m}-c_{r}>0$ \\
$b$ & A unit transfer price of a returned waste product that the manufacturer paid to the third-party \\
$A$ & A unit transfer payment made by the third-party to a consumer when recycling waste products. In \\
& order to make recycling waste products economically feasible, obviously $b-A>0$ \\
& Recycling rate of waste products, $0 \leq \tau \leq 1$ \\
$p$ & Retail price of new product \\
$d$ & The profit donation amount for the retailer per unit sell (the retailer's CSR investment level) \\
$r$ & The manufacturer's CSR behavior consciousness strength, $0<r<1$ \\
$c(\tau)$ & The investment cost of the third-party in collection activity. Refer to Savaskan et al. [45] etc., assume \\
& $c(\tau)=k \tau^{2}$, where $k$ represents the scale parameter and $k>0$ \\
$h(d)$ & The base cost of the retailer's CSR investment. Refer to Modak et al. [36], assume $h(d)=g d^{2}$, \\
& where $g$ represents the retailer's scale parameter and $g>0$ \\
$\pi_{X}^{i}$ & The pure profits obtained by the decision maker $X$ under $i$ decision model, where $i=$ \\
& $\{\mathrm{N}$, MR, MT, MRT $\}$ represents the N model, MR model, MT model and MRT model, respectively. \\
& $X=\{m, r, t, s\}$ represents the manufacturer, retailer, third-party and the CSR-CLSC system, \\
$V_{X}^{i}$ & respectively. \\
& The total profits obtained by the decision maker $X$ under $i$ decision model. \\
\hline
\end{tabular}

shown are: (1) the decentralized decision model that does not have any cooperation among the players (Model N, see Fig. 1a), (2) the decision-making model where the manufacturer only cooperates with the retailer (Model MR, see Fig. 1b), (3) the decision-making model where the manufacturer only cooperates with the third-party (Model MT, see Fig. 1c), (4) the centralized decision-making model for cooperation among the manufacturer, retailer and third-party (Model MRT, see Fig. 1d). With reference to the research hypotheses of Ma et al. [34], we use the decentralized and centralized decision models as benchmark to compare and analyze the effect of different cooperative strategies of manufacturer on the decision efficiency of CSR-CLSC.

\subsection{Model notations and assumptions}

Based on the problem description, for clarity, we define the model notations in Table 1.

Based on the principle of realism and analysis tractable of model construction, and reference related literature, we introduce the following assumptions.

Assumption 3.1. Referring to the research of [17, 30, 45,56], it is assumed that there is no difference between the new product and remanufactured product. In other words, suppose that the manufacturer can integrate the remanufacturing process of waste products into the original production system and directly produce new products through raw materials or recycled waste products [45]. For example, HP considers its remanufactured computers to be no different from the new computers and sells them to consumers in the same market at the same price [9]. The Kodak line of single use cameras was another example for this case, and most consumers did not know the reality that their newly bought cameras contain "remanufactured parts" (even though it was clearly stated on the packaging) [7].

Assumption 3.2. Referring to Modak et al. [36], the retailer's profit-donating behavior (CSR investment behavior) can also bring a good reputation to itself, which directly affects the market demand for new products. So, the market demand function is

$$
q=a-\beta p+\theta d
$$


where, a represents the market potential of the new product, $a>0, p$ represents the retail price of the retailer's new product, $\beta$ represents the price sensitivity of consumers to new products, $d$ represents the amount of direct donation (CSR investment level) by the retailer to a social good organization for each unit of new product sale, $\theta$ represents the sensitivity coefficient of consumers to CSR investment level, $a>\beta p$ ensures that under any circumstance the demand at the retailer's end is non-negative, $\theta>\beta>0, \theta>\beta$ indicates that consumers are more sensitive to the CSR investment level than the retail price [36, 49].

Assumption 3.3. In the modeling and analysis, it is considered the effects of the manufacturer's CSR in the form of consumer surplus [26, 43]. Consumer surplus is the difference between the maximum price that the consumers are willing to pay for a product and the market price that they actually pay for the product [26, 43]. Thus, the consumer surplus is given by

$$
\mathrm{CS}=\int_{p_{\min }}^{p_{\max }} q \mathrm{~d} p=\int_{\frac{a+\theta d-q}{\beta}}^{\frac{a+\theta d}{\beta}}(a-\beta p+\theta d) \mathrm{d} p=\frac{(a-\beta p+\theta d)^{2}}{2 \beta}
$$

$r \in(0,1)$ is strength of the manufacturer's CSR behavior consciousness then it incorporates $\frac{r q^{2}}{2 \beta}$ as consumer surplus in its total profits.

Assumption 3.4. In order to ensure the optimal recycling rate is bounded within a given range $(0 \leq \tau \leq 1)$, the profit functions of CSR-CLSC members are concave, and the related expressions have certain economic feasibility. Consistent with previous research [45,56], the scaling parameters are assumed to be sufficiently large, that is, $k>\max \left\{\frac{g \beta^{2} \Delta_{1}^{2}}{2 g \beta(2-r)-(\theta-\beta)^{2}}, \frac{\beta \Delta_{1}^{2}}{2(1-r)}\right\}, g>\frac{(\theta-\beta)^{2}}{2 \beta(2-r)}$.

\section{Game models of CSR-CLSC}

This section mainly constructs the decision-making models under manufacturer's four cooperation strategies in CSR-CLSC, namely, Model N, Model MR, Model MT and Model MRT. At the same time, we obtain the optimal solutions of each model by using reverse recursive method (see Appendix A for detailed solution process), and for clarity, the equilibrium results of all models are shown in Table 2.

\subsection{Decentralized decision-making model without cooperative strategy (Model N)}

In the model N (as shown in Fig. 1a), the manufacturer decides the wholesale price and unit transfer price, and exhibits CSR, its total profits are the sum of pure profit and the consumer surplus that it accrues from the stakeholders. The retailer determines the retail price of the product and the amount that each sales unit can donate (CSR investment level). The third-party decides the recycling rate of waste products. The profit functions of CSR-CLSC members can be expressed as

$$
\begin{aligned}
V_{m}^{\mathrm{N}}(w, b) & =\pi_{m}^{\mathrm{N}}(w)+r \mathrm{CS} \\
& =\left(w-c_{m}\right)(a-\beta p+\theta d)+\left(\Delta_{0}-b\right) \tau(a-\beta p+\theta d)+r \frac{(a-\beta p+\theta d)^{2}}{2 \beta} \\
\pi_{r}^{\mathrm{N}}(p, d) & =(p-w-d)(a-\beta p+\theta d)-g d^{2} \\
\pi_{t}^{\mathrm{N}}(\tau) & =(b-A) \tau(a-\beta p+\theta d)-k \tau^{2} .
\end{aligned}
$$

\subsection{Decision-making model when the manufacturer only cooperates with the retailer (Model MR)}

In the model MR (as shown in Fig. 1b), the manufacturer and the retailer build a coalition with one another and are viewed as a central planner. The central planner decides the retail price, transfer price and CSR 
TABLE 2. Equilibrium results under different models.

\begin{tabular}{|c|c|c|c|c|}
\hline & Model N $(i=\mathrm{N})$ & Model MR $(i=\mathrm{MR})$ & Model MT $(i=\mathrm{MT})$ & Model MRT $(i=\mathrm{MRT})$ \\
\hline$w^{i *}$ & $\underline{a g \Delta_{2}+\Delta_{3}}$ & Null & $\underline{a g \beta \Delta_{14}+\Delta_{15}}$ & Null \\
\hline$\tau^{i *}$ & $\underline{\underline{g \beta\left(a-\beta c_{m}\right) \Delta_{1}}}$ & $\underline{g \beta\left(a-\beta c_{m}\right) \Delta_{1}}$ & $\underline{\underline{g \beta\left(a-\beta c_{m}\right) \Delta_{1}}}$ & $\underline{g \beta\left(a-\beta c_{m}\right) \Delta_{1}}$ \\
\hline$d^{i *}$ & $\underline{2 k(\theta-\beta)^{4}\left(a-\beta c_{m}\right)}$ & $\begin{array}{c}\Delta_{10} \\
\underline{2 k(\theta-\beta)\left(a-\beta c_{m}\right)} \\
\end{array}$ & $\underline{k(\theta-\hat{\beta})\left(a-\beta c_{m}\right)}$ & $\stackrel{\Delta(\theta-\hat{\beta})\left(a-\beta c_{m}\right)}{(a)}$ \\
\hline$p^{i *}$ & $\begin{array}{c}\Delta_{4} \\
a g \beta \Delta_{5}+\Delta_{6}\end{array}$ & $\begin{array}{c}\Delta_{10} \\
a g \Delta_{11}+\Delta_{12} \\
\end{array}$ & $\begin{array}{c}\Delta_{16} \\
a g \beta \Delta_{17}+\Delta_{18} \\
n_{11}\end{array}$ & $\begin{array}{c}\Delta_{20} \\
a g \Delta_{21}+\Delta_{22} \\
\end{array}$ \\
\hline$q^{i *}$ & $\underline{4 k g \beta\left(a-\beta c_{m}\right)}$ & $\underline{4 k g \hat{\beta}\left(a-\beta c_{m}\right)}$ & $\begin{aligned} \beta \Delta_{16} \\
\underline{2 k g \beta\left(a-\beta c_{m}\right)}\end{aligned}$ & $\underline{2 k g \beta\left(a-\beta c_{m}\right)}$ \\
\hline$b^{i *}$ & ${\frac{\Delta_{0}+A}{\Delta_{4}}}_{2}^{2}$ & ${\frac{\Delta_{0}+A}{\Delta^{\prime}}}^{2}$ & $\mathrm{Null}^{\Delta_{16}}$ & $\mathrm{Null}^{\Delta_{20}}$ \\
\hline$\pi_{m}^{i *}$ & $\frac{2 k g\left(a-\beta c_{m}\right)^{2} \Delta_{7}}{\Delta_{4}{ }^{2}}$ & $\frac{2 k g\left(a-\beta c_{m}\right)^{2} \Delta_{13}}{\Delta_{1} 0^{2}}$ & $\frac{k g\left(a-\beta c_{m}\right)^{2} \Delta_{10}}{\Delta_{1} \sigma^{2}}$ & Null \\
\hline$V_{m}^{i *}$ & $\underline{2 k g\left(a-\beta c_{m}\right)^{2}}$ & $\underline{2 k g\left(a-\beta c_{m}\right)^{2}}$ & $\underline{k g\left(a-\beta c_{m}\right)^{2}}$ & Null \\
\hline$\pi_{r}^{i *}$ & $\frac{4 k^{2} g\left(a-\beta c_{m}\right)^{2} \Delta_{8}^{2}}{\Delta_{4}^{2}}$ & Null $^{\Delta_{10}}$ & $\frac{k^{2} g\left(a-\beta c_{m}\right)^{2} \Delta_{8}}{\Delta_{1} \sigma^{2}}$ & Null \\
\hline$\pi_{t}^{i *}$ & $\frac{k g^{2} \beta^{2}\left(a-\beta c_{m}\right)^{2} \Delta_{1}^{2}}{\Delta_{4}^{2}}$ & $\frac{k g^{2} \beta^{2}\left(a-\beta c_{m}\right)^{2} \Delta_{1}^{2}}{\Delta_{1}^{2} 0^{2}}$ & Null & Null \\
\hline$\pi_{s}^{i *}$ & $\frac{k g\left(a-\beta c_{m}\right)^{2} \Delta_{9}}{\Delta_{4}{ }^{2}}$ & $\frac{k g\left(a-\beta c_{m}\right)^{2} \Delta_{7}}{\Delta_{10^{2}}{ }^{2}}$ & $\frac{k g\left(a-\beta c_{m}\right)^{2} \Delta_{19}}{\left.\Delta_{16}\right)^{2}}$ & $\frac{k g\left(a-\beta c_{m}\right)^{2}}{\Delta_{20}}$ \\
\hline
\end{tabular}

investment level. The third-party decides the recycling rate of waste products. The profit functions of CSRCLSC members can be expressed as

$$
\begin{aligned}
V_{m}^{\mathrm{MR}}(p, b, d) & =\pi_{m}^{\mathrm{MR}}(p, d)+r \mathrm{CS} \\
& =\left(p-c_{m}-d\right)(a-\beta p+\theta d)+\left(\Delta_{0}-b\right) \tau(a-\beta p+\theta d)-g d^{2}+r \frac{(a-\beta p+\theta d)^{2}}{2 \beta} \\
\pi_{t}^{\mathrm{MR}}(\tau) & =(b-A) \tau(a-\beta p+\theta d)-k \tau^{2} .
\end{aligned}
$$

\subsection{Decision-making model when the manufacturer only cooperates with the third party (Model MT)}

In the model MT (as shown in Fig. 1c), the manufacturer and the third-party build a coalition with one another and are viewed as a central planner. The central planner decides the wholesale price, transfer price and recycling rate of waste products. The retailer decides the retail price and CSR investment level. The profit function of CSR-CLSC members can be expressed as

$$
\begin{aligned}
V_{m}^{\mathrm{MT}}(w, b, \tau) & =\pi_{m}^{\mathrm{MT}}(w, \tau)+r \mathrm{CS} \\
& =\left(w-c_{m}\right)(a-\beta p+\theta d)+\left(\Delta_{0}-A\right) \tau(a-\beta p+\theta d)-k \tau^{2}+r \frac{(a-\beta p+\theta d)^{2}}{2 \beta} \\
\pi_{r}^{\mathrm{MT}}(p, d) & =(p-w-d)(a-\beta p+\theta d)-g d^{2} .
\end{aligned}
$$

\subsection{Centralized decision-making model when manufacturers cooperate with the retailer and third party (Model MRT)}

In the model MRT (as shown in Fig. 1d), the manufacturer also integrates the retailer and third-party to adopt a cooperative strategy, namely all members enter into an alliance with one another and act as a single entity. Therefore, there is only a single decision maker, and the central planner decides the retail price, CSR investment level and recycling rate of waste products. Hence, the profit function of the central planner can be expressed as 


$$
V_{s}^{\mathrm{MRT}}(p, d, \tau)=\left(p-c_{m}-d\right)(a-\beta p+\theta d)+\left(\Delta_{0}-A\right) \tau(a-\beta p+\theta d)-g d^{2}-k \tau^{2}+r \frac{(a-\beta p+\theta d)^{2}}{2 \beta}
$$

where, $c_{m}-c_{r}-A=\Delta_{1}, 4 k(2-r)-\beta \Delta_{1}^{2}=\Delta_{2}, 8 k g \beta^{2} c_{m}-2 k\left(a+\beta c_{m}\right)(\theta-\beta)^{2}=\Delta_{3}$, $g \beta\left(4 k(4-r)-\beta \Delta_{1}{ }^{2}\right)-4 k(\theta-\beta)^{2}=\Delta_{4}, 4 k(3-r)-\beta \Delta_{1}{ }^{2}=\Delta_{5}, 4 k g \beta^{2} c_{m}+2 k(\theta-\beta)\left(2 a \beta-\theta\left(a+\beta c_{m}\right)\right)=\Delta_{6}$, $g \beta\left(8 k(2-r)-\beta \Delta_{1}^{2}\right)-4 k(\theta-\beta)^{2}=\Delta_{7}, 4 g \beta-(\theta-\beta)^{2}=\Delta_{8}, g \beta\left(8 k(6-r)-\beta \Delta_{1}^{2}\right)-12 k(\theta-\beta)^{2}=\Delta_{9}$, $g \beta\left(4 k(2-r)-\beta \Delta_{1}^{2}\right)-2 k(\theta-\beta)^{2}=\Delta_{10}, 4 k(1-r)-\beta \Delta_{1}^{2}=\Delta_{11}, 4 k g \beta c_{m}+2 k(\theta-\beta)\left(a-\theta c_{m}\right)=\Delta_{12}$, $g \beta\left(8 k(1-r)-\beta \Delta_{1}{ }^{2}\right)-2 k(\theta-\beta)^{2}=\Delta_{13}, 2 k(2-r)-\beta \Delta_{1}^{2}=\Delta_{14}, 4 k g \beta^{2} c_{m}-k\left(a+\beta c_{m}\right)(\theta-\beta)^{2}=\Delta_{15}$, $g \beta\left(2 k(4-r)-\beta \Delta_{1}^{2}\right)-2 k(\theta-\beta)^{2}=\Delta_{16}, 2 k(3-r)-\beta \Delta_{1}^{2}=\Delta_{17}, 2 k g \beta^{2} c_{m}+k(\theta-\beta)\left(2 a \beta-\theta\left(a+\beta c_{m}\right)\right)=$ $\Delta_{18}, g \beta\left(2 k(6-r)-\beta \Delta_{1}^{2}\right)-3 k(\theta-\beta)^{2}=\Delta_{19}, g \beta\left(2 k(2-r)-\beta \Delta_{1}^{2}\right)-k(\theta-\beta)^{2}=\Delta_{20}, 2 k(1-r)-\beta \Delta_{1}^{2}=$ $\Delta_{21}, 2 k g \beta c_{m}+k(\theta-\beta)\left(a-\theta c_{m}\right)=\Delta_{22}$. Under the assumption of scale parameter $k, g, \Delta_{1}, \Delta_{2}, \cdots, \Delta_{22}>0$.

\section{Equilibrium RESULT ANALYSiS}

\subsection{Analysis of the impact of CSR on CSR-CLSC decision and performance}

This section mainly analyzes the impact of CSR on the operation of CSR-CLSC. Firstly, it discussed that the interaction between manufacturer's CSR behavior consciousness and retailer's CSR investment. Secondly, it analyzed the impact of manufacturer's CSR behavior consciousness on the operation and performance of CSR-CLSC. Finally, it investigated that the impact of consumer's sensitivity to retailer's CSR investment on the performance of CSR-CLSC. Since the relevant conclusions of manufacturer's different cooperation strategies are similar, we mainly analyze the decentralized decision model (Model N) in this section (see Appendix A for all certification processes).

Proposition 5.1. In the CSR-CLSC, $\frac{\partial d^{\mathrm{N}^{*}}}{\partial r}>0$.

Proposition 5.1 shows that in the CSR-CLSC, as the increases of manufacture's CSR behavior consciousness, the retailer will also actively increase CSR investment levels. In fact, the increase of manufacturer's CSR behavior consciousness means that the manufacturer will share more pure profit to achieve the purpose of benefiting stakeholders and increasing social welfare, and the retailer can also benefit from it.

In fact, the strengthening of dominant manufacturer's CSR behavior consciousness means that the manufacturer can benefit the stakeholders by actively sharing her pure profit, which will also benefit the retailer (Prop. 5.3 shows that the retailer's profit and the CSR behavior consciousness level of manufacturer is directly proportional), so the retailer will actively increase the CSR investment levels in order to respond and motivate the dominant manufacturer to further enhance the CSR behavior consciousness.

Proposition 5.2. In the CSR-CLSC, $\frac{\partial \tau^{\mathrm{N}^{*}}}{\partial r}>0, \frac{\partial w^{\mathrm{N}^{*}}}{\partial r}<0, \frac{\partial p^{\mathrm{N}^{*}}}{\partial r}<0, \frac{\partial q^{\mathrm{N}^{*}}}{\partial r}>0$.

Proposition 5.2 shows that in the CSR-CLSC, with the strengthening of manufacture's CSR behavior consciousness, it can not only encourage the third-party to increase the recycling rate of used products, but also reduce the wholesale and retail prices of new products and increase the market demand. This is because as the manufacture's CSR behavior consciousness increasing, the dominant manufacturer will actively reduce the wholesale price of new products to better benefit her stakeholders, thereby achieving the purpose of maximizing social welfare (Prop. 5.3 also shows that the manufacturer's social welfare maximization goal is positively proportional to her CSR behavior consciousness). On the one hand, this kind of active profit-making behavior will encourage the retailer to lower the retail price of new products, on the other hand, it will also encourage the third-party to increase the recycling rate of used products. At the same time, the increase in the recycling rate of waste products has further reduced the manufacturer's production costs and brought greater marginal benefits, thus achieving a positive feedback cycle and stable operation in CSR-CLSC. Combined with the Proposition 5.1, the retailer will also increase her CSR investment level, so the market demand for new products will also increase. 
Under the channel structure when the retailer recycling, Panda et al. [43] pointed out that as the manufacturer's CSR behavior consciousness increasing, the retailer will actively reduce the retail price of new products and strive to increase the recycling rate of waste products in response to the manufacturer's CSR behavior. We show that when the third-party is responsible for the recycling of waste products, the manufacturer's CSR behavior consciousness can not only incentivize the retailer to reduce the retail price of new products and the third-party to increase the recycling rate of waste products, but also incentivize the retailer to increase her CSR investment level.

Combining Propositions 5.1 and 5.2, the manufacturer actively fulfills the CSR, which not only effectively reduces the wholesale and retail prices of new products, but also effectively incentivizes the retailer to increase CSR investment level and encourage the third-party to improve the recycling rate, and finally reaches the purpose of reducing the production cost of new products and stimulating market demand. Therefore, the manufacturer actively improves her CSR behavior consciousness, which is not only conducive to the sale of new products and the recycling rate of waste products, but also can effectively promote the stable operation of CSR-CLSC.

Proposition 5.3. In the CSR-CLSC, $\frac{\partial \pi_{m}^{\mathrm{N}^{*}}}{\partial r}<0, \frac{\partial V_{m}^{\mathrm{N}^{*}}}{\partial r}>0, \frac{\partial \pi_{r}^{\mathrm{N}^{*}}}{\partial r}>0, \frac{\partial \pi_{t}^{\mathrm{N}^{*}}}{\partial r}>0, \frac{\partial V_{s}^{\mathrm{N}^{*}}}{\partial r}>0$.

Proposition 5.3 shows that in the CSR-CLSC, with the strengthening of manufacture's CSR behavior consciousness, although the manufacturer's pure profit is decreasing, her social welfare, the profits of CSR-CLSC members and whole system are all increasing. This is because as the manufacturer's CSR behavior consciousness increasing, the manufacturer will sacrifice part of her pure profit in exchange for the increase in the overall profit of other members and social welfare, while achieving her goal of maximizing social welfare. Combining Propositions 5.1 and 5.2, the increase of the manufacturer's CSR behavior consciousness can not only effectively improve the recycling rate, to achieve environmental protection and green sustainable development goals, but also improve the performance of CSR-CLSC.

Proposition 5.3 reveals that the dominant manufacturer's CSR behavior consciousness is always beneficial to the stable operation of CSR-CLSC. If the manufacturer's CSR behavior consciousness is stronger, the more sacrifice it makes on pure profit, the greater contribution it will make to social welfare. Therefore, the manufacturer as the leader should take the initiative to undertake CSR, which can not only improve the performance of CSR-CLSC, increase social welfare, but also achieve a "win-win" situation.

\section{Proposition 5.4. In the CSR-CLSC,}

(1) $\frac{\partial w^{\mathrm{N}^{*}}}{\partial \theta}<0, \frac{\partial \tau^{\mathrm{N}^{*}}}{\partial \theta}>0, \frac{\partial d^{\mathrm{N}^{*}}}{\partial \theta}>0, \frac{\partial p^{\mathrm{N}^{*}}}{\partial \theta}>0, \frac{\partial q^{\mathrm{N}^{*}}}{\partial \theta}>0$;

(2) $\frac{\partial \pi_{m}^{\mathrm{N}^{*}}}{\partial \theta}>0, \frac{\partial V_{m}^{\mathrm{N}^{*}}}{\partial \theta}>0, \frac{\partial \pi_{r}^{\mathrm{N}^{*}}}{\partial \theta}>0, \frac{\partial \pi_{t}^{\mathrm{N}^{*}}}{\partial \theta}>0, \frac{\partial \pi_{s}^{\mathrm{N}^{*}}}{\partial \theta}>0$.

Proposition 5.4 shows that in the CSR-CLSC, as consumers become more sensitive to the retailer's CSR investment, the wholesale price of new products will decrease, and the retail price of new products, market demand, the retailer's CSR investment level, and waste product recycling rate will all increase. At the same time, the profits of CSR-CLSC members and whole system will also increase.

As consumers become more sensitive to the retailer's CSR investment, the retailer will inevitably increase her CSR investment level in order to attract more consumers, and this will lead to the increase of retailer's CSR investment costs. Therefore, the retailer will make up for her losses in CSR investment by increasing retail prices. However, the increase in retail prices will not significantly affect consumer demand, because consumers are also more willing to pay for companies that actively undertake CSR, so the market demand of new products has increased. At the same time, the dominant manufacturer will actively reduce wholesale prices for giving more profit to the retailer, which will encourage the retailer to make more CSR investment, so as to achieve the purpose of stimulate consumption and increase the recycling rate of waste products, reduce production costs and improve her income. This further reveal that the manufacturer's CSR behaviour consciousness and the retailer's CSR investment have a mutually inspiring effect, and both can benefit consumers, the environment and CSR-CLSC system. Further, although the manufacturer's active profit-making activities will lose part of benefits, but due to the increase in market demand for new products and the recycling rate of waste products, 
the pure profit and social welfare of the manufacturer will also increase, and then the profits of CSR-CLSC members and whole system will also increase.

\subsection{Comparative analysis of different cooperation strategy of manufacturer}

This section mainly investigates the impact of CSR on the choice of manufacturer's cooperation strategies and the performance of CSR-CLSC. Firstly, it compares the equilibrium results of different manufacturer's cooperation strategies; secondly, it discusses the different cooperation strategies and cooperation motivations of the manufacturer, retailer, and third-party. Finally, we compare and analyze the overall performance of CSR-CLSC under different cooperation strategies (see Appendix A for all certification processes).

Proposition 5.5. In the CSR-CLSC, under the different cooperation strategy of the dominant manufacturer, the optimal transfer payment and wholesale price satisfy $b^{\mathrm{N}^{*}}=b^{\mathrm{MR}^{*}}=\frac{\Delta_{0}+A}{2}, w^{\mathrm{N}^{*}}>w^{\mathrm{MT}^{*}}$.

Proposition 5.5 shows that in the CSR-CLSC, the optimal transfer payment for the third-party is the same when the manufacturer does not adopt/adopts the cooperative strategy with the retailer. When the manufacturer does not adopt the cooperative strategy, the wholesale price of the new product is higher than that when she cooperates with the third-party.

This is because regardless of whether the manufacturer cooperates with the retailer, the marginal profit brought to the manufacturer by the remanufacturing of unit waste products is always $\Delta_{0}-b$, and the marginal profit brought to the third-party by the unit waste product recycling is always $b-A$. If the manufacturer increases the transfer payment price to the third-party, her revenue is bound to decrease; if the manufacturer reduces the transfer payment price to the third-party, the third-party's marginal profit will inevitably decrease. Therefore, in order to balance the marginal income of herself and the third-party, the manufacturer's optimal transfer payment to the third-party is $b^{\mathrm{N}^{*}}=b^{\mathrm{MR}^{*}}=\frac{\Delta_{0}+A}{2}$. When the manufacturer cooperates with the third-party, it completely internalizes the cost savings of remanufacturing in reverse logistics, and further improves the marginal profit of the manufacturer's remanufacturing. Therefore, at this time, the manufacturer will strategically reduce the wholesale price of new products to stabilize her market leadership.

Proposition 5.6. In the CSR-CLSC, under the different cooperation strategy of the dominant manufacturer, the optimal recycling rates satisfy $\tau^{\mathrm{MRT}^{*}}>\tau^{\mathrm{MR}^{*}}>\tau^{\mathrm{MT}^{*}}>\tau^{\mathrm{N}^{*}}$.

Proposition 5.6 shows that in the CSR-CLSC, it is always beneficial for the manufacturer to cooperate with the retailer or third-party to improve the recycling rate of waste products. Specifically, the recycling rate of waste products is the highest when the manufacturer cooperates with the retailer and third-party, and the lowest when neither of them cooperate. Moreover, compared with the cooperation between the manufacturer and third-party, when the manufacturer cooperates with the retailer, it is more conducive to improving the recycling rate of waste products.

In the CLSC without CSR, Shi et al. [46] showed that the recycling rate of waste products was higher when the manufacturer cooperated with the third-party than with the retailer. We further reveal that in the CSRCLSC, the recycling rate of waste products will be higher when the manufacturer cooperates with the retailer than that with the third-party. Therefore, CSR behavior is also an important factor affecting the choice of cooperation strategy for the manufacturer.

Proposition 5.7. In the CSR-CLSC, under the different cooperation strategy of the dominant manufacturer, the optimal CSR investment levels satisfy $d^{\mathrm{MRT}^{*}}>d^{\mathrm{MR}^{*}}>d^{\mathrm{MT}^{*}}>d^{\mathrm{N}^{*}}$, the optimal retail prices satisfy $p^{\mathrm{N}^{*}}>p^{\mathrm{MT}^{*}}>p^{\mathrm{MR}^{*}}>p^{\mathrm{MRT}^{*}}$, the optimal market demands satisfy $q^{\mathrm{MRT}^{*}}>q^{\mathrm{MR}^{*}}>q^{\mathrm{MT}^{*}}>q^{\mathrm{N}^{*}}$.

Proposition 5.7 shows that in the CSR-CLSC, the cooperation between the manufacturer and retailer or the third-party is always conducive to reducing the retail price of new products, increasing the CSR investment level and market demand. Specifically, when the manufacturer cooperates with the retailer and third-party, the retail price of new products is the lowest, CSR investment level and market demand are the highest. When there is no cooperation among the manufacturer, retailer and third-party, the retail price of new products is the highest, the 
CSR investment level and market demand are the lowest. In addition, compared with the cooperation between the manufacturer and third-party, the cooperation between the manufacturer and retailer is more conducive to reducing the price of new products, increasing CSR investment level and market demand.

Combining Propositions 5.6 and 5.7, in the CSR-CLSC, the manufacturer's cooperation strategy is always conducive to lowering the retail price of new products, increasing the CSR investment level and recycling rate of waste products. Specifically, the centralized decision-making model when the manufacturer cooperates with the retailer and third-party is always better than the other, and the cooperation model when the manufacturer cooperates retailer is also better than that with the third-party.

Proposition 5.8. In the CSR-CLSC, under the different cooperation strategy of the dominant manufacturer, when the manufacturer cooperates with the retailer, the profits satisfy $V_{m}^{\mathrm{MR}^{*}}>V_{m}^{\mathrm{N}^{*}}+\pi_{r}^{\mathrm{N}^{*}}, \pi_{t}^{\mathrm{MR}^{*}}>\pi_{t}^{\mathrm{N}^{*}}$. When the manufacturer cooperates with the third-party, the profits satisfy $V_{m}^{\mathrm{MT}^{*}}>V_{m}^{\mathrm{N}^{*}}+\pi_{t}^{\mathrm{N}^{*}}, \pi_{r}^{\mathrm{MT}^{*}}>\pi_{r}^{\mathrm{N}^{*}}$. The profits in two different cooperation models satisfy $V_{m}^{\mathrm{MR}^{*}}-V_{m}^{\mathrm{N}^{*}}-\pi_{r}^{\mathrm{N}^{*}}>V_{m}^{\mathrm{MT}^{*}}-V_{m}^{\mathrm{N}^{*}}-\pi_{t}^{\mathrm{N}^{*}}$.

Proposition 5.8 shows that in the CSR-CLSC, the cooperation between the manufacturer and retailer or the third-party not only helps to increase the profits of the alliance, but also helps to increase the profit of the enterprise that have not participated in the cooperation of CLSC. Specifically, the manufacturer has profit and social welfare motives to cooperate with the retailer or third-party, and the profit and social welfare motive for cooperation with the retailer is stronger. At the same time, the retailer or third-party also benefit from the manufacturer's cooperation strategy.

This is because when the manufacturer and retailer cooperate, the channel conflict of profits in the forward supply chain is avoided, the double marginal effect is weakened, and the market demand for new products is effectively increased, so the third-party's revenue can be increased. When the manufacturer cooperates with the third-party, it completely internalizes the cost savings of remanufacturing, and at the same time, the recycling rate of waste products is improved, reducing the production cost of new products, so that the manufacturer and third-party get more profits. The reduction in wholesale prices has increased the retailer's marginal revenue, and the market demand for new products has also increased, so the retailer can also benefit from the cooperation between the manufacturer and third-party.

Proposition 5.9. In the CSR-CLSC, under the different cooperation strategy of the dominant manufacturer, we have $V_{s}^{\mathrm{MRT}^{*}}>V_{s}^{\mathrm{MR}^{*}}>V_{s}^{\mathrm{MT}^{*}}>V_{s}^{\mathrm{N}^{*}}$.

Proposition 5.9 shows that in the CSR-CLSC, the manufacturer's cooperation strategy is always conducive to increasing the consumer surplus and improving the profits of CSR-CLSC and social welfare. Specifically, when the manufacturer cooperates with the retailer and third-party, the total profits of CSR-CLSC is the largest, followed only by cooperation with the retailer, and the smallest when they are not cooperated.

Combining Propositions 5.8 and 5.9, from the perspective of increasing profits and social welfare, the manufacturer, retailer and third-party all have incentives to participate in cooperation. And the manufacturer's cooperation strategy is conducive to increasing the profits and decision-making efficiency of CSR-CLSC and social welfare. The manufacturer may be apt to cooperate with the retailer rather than the third-party.

To sum up, in the CSR-CLSC, the manufacturer's cooperation strategy is not only conducive to improving the recycling rate of waste products, the CSR investment level and new product market demand, but also conducive to increasing the total profits of CSR-CLSC and increasing the consumer surplus to improve social welfare. Compared to cooperate the third-party, the manufacturer is more inclined to cooperate with the retailer. And the cooperation between the manufacturer and retailer is also more conducive to improving the recycling rate of waste products, the CSR investment level and consumer surplus. Therefore, the government could make some incentive policies to promote the cooperation between the manufacturer and retailer, so as to improve the recycling rate of waste products and CSR investment level of enterprises. 


\section{NumericAl ANALYSis}

Comprehensively considering the hypothetical conditions of the models, and combining the relevant literature, such as Modak et al. [36], Panda et al. [43], and so on, we set the experimental parameters as follows: $a=120$, $\beta=1, c_{m}=60, c_{r}=30, A=10, k=600, g=80$. According to the relevant research results in this paper, the specific simulation results are shown in Figures 2-6.

Figures 2-5 show that under four decision models, the enhancement of manufacturer's CSR behavior consciousness and the increase of consumers's sensitivity to retailer's CSR investment level are conducive to reducing the retail price of new products and improving retailer's CSR investment level, recycling rate of waste products and market demand. At the same time, in terms of reducing the retail price of new products, improving the CSR investment level, the recovery rate of waste products and the market demand of new products, the strategy of simultaneous cooperation among the manufacturer, retailer and third-party is the best, followed by cooperation only with retailer, and the worst when there is no cooperation. Further, it can be found that compared with the cooperation between manufacturer and retailer and third-party at the same time or between manufacturer and retailer, the cooperation between manufacturer and third-party has no significant effect on improving the recovery rate of waste products and the market demand of new products. This also explains why many manufacturers prefer to integrate retail channels and implement the forward integration strategy rather than engage in the recycling and remanufacturing of waste products.

Figures 2-5 further reveal that the stronger the sense of social responsibility of consumers and the more members involved in cooperation in the CSR-CLSC, the more conducive it is to improve the CSR investment level, the recovery rate of waste products and the market demand. Therefore, as the regulator of the market, on the one hand, the government can improve consumers' awareness of social responsibility through publicity and education. On the other hand, it can also promote the cooperation of member enterprises in the CSR-CLSC through certain policies, so as to effectively realize the coordinated development of society, environment and economy.

Management enlightenment: Firstly, from the perspective of dominant manufacturing enterprises, while enhancing their CSR behavior consciousness, they should also strengthen the cooperation with retailers and third-parties. By strengthening the cooperation among supply chain members, they can further enlarge the economic and environmental benefits brought by the implementation of CSR, win a better social reputation and truly realize sustainable development. Secondly, from the perspective of retailers, they should be aware that the enhancement of consumers' social responsibility consciousness can effectively amplify the advantages brought by manufacturers' CSR behavior. By strengthening consumers' social responsibility consciousness, they can create more profits on the premise of protecting the environment, resources and social benefits to the greatest extent. Finally, from the perspective of consumers, the public also needs to strengthen their awareness of social responsibility and environmental protection, learn to develop green and low-carbon consumption habits, and then standardize the social and environmental responsibility behavior of enterprises through the power of market.

Figure 6 shows that as the manufacturer's CSR behavior consciousness increasing, the total profits of CSRCLSC under all decision models are increasing. At the same time, it can be found that the manufacturer's cooperation strategy is always conducive to the increase of total profits of CSR-CLSC, and the more members participate in the cooperation, it will be better to the CSR-CLSC.

In fact, it is easy to find that compared with the integration of reverse supply chain, the integration of forward supply chain usually brings greater benefits, so the manufacturer should strengthen the vertical cooperation with the retailer. For example, after Huawei and Suning reached a strategic cooperation, they jointly reached the strategic goal of 30 billion sales in three years, which not only achieved their own performance improvement, but also drove the development of the entire supply chain.

Management enlightenment: Manufacturers should strengthen the control and integration of the forward supply chain through acquisition, self construction and combination. Through the implementation of positive 


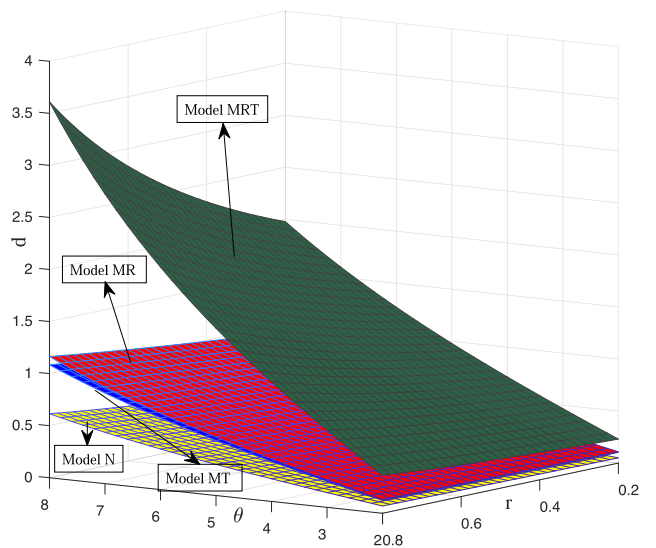

Figure 2. Impact of the $\theta$ and $r$ on CSR investment levels.

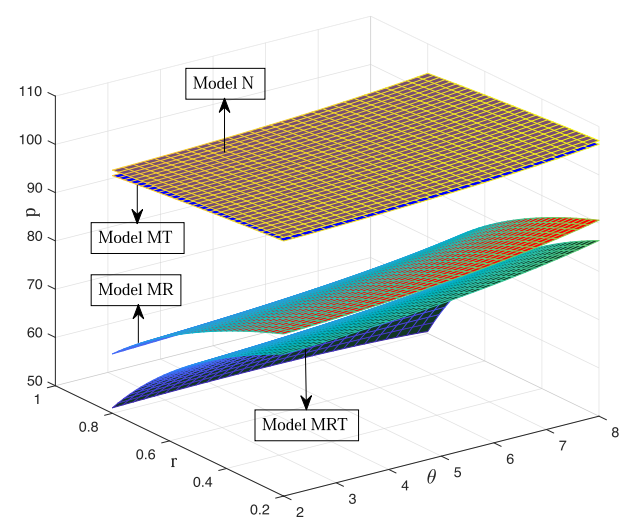

Figure 4. Impact of the $\theta$ and $r$ on retail prices.

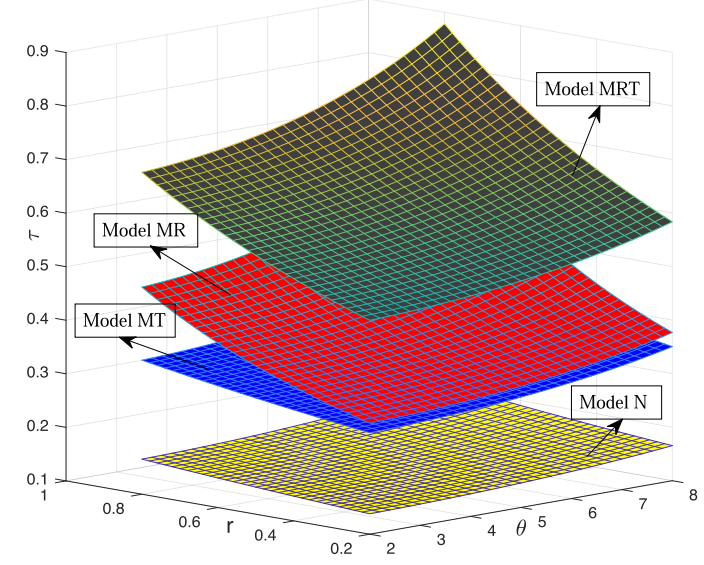

FiguRE 3. Impact of the $\theta$ and $r$ on recycling rates.

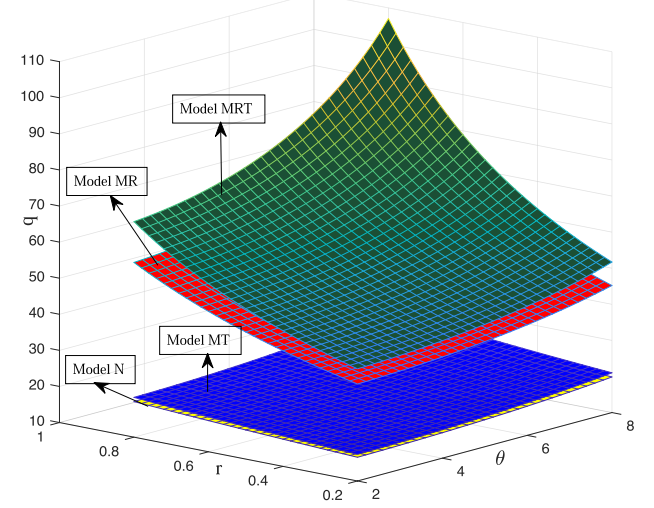

Figure 5. Impact of the $\theta$ and $r$ on market demand.

forward integration strategy, they can not only better explore the market, but also realize the improvement performance of themselves and the overall supply chain.

\section{Conclusions, managerial insights, AND FUture StUdies}

Integrating the CSR into CLSC has evolved as an implement for firms to maximize profitability and also contributes to improving environmental performance and social welfare. So, this study develops CSR-CLSC models that takes into account the consumer surplus, profit donation (CSR investment) and recycling simultaneously under the price-and-CSR investment deterministic demand. And in order to investigate the impact of CSR on manufacturer's cooperation strategies, in addition to building a basic decentralized decision-making model (Model N), we further extended CSR to the following three manufacturer's cooperation models, namely the manufacturer only cooperates with the retailer (Model MR), the manufacturer only cooperates with the thirdparty (Model MT), the centralized decision-making model for cooperation among the manufacturer, retailer and third-party (Model MRT). We solve these cooperative models and make a detailed analysis and careful comparison of the results in various cooperative models. And we investigate the interaction between the manufacturer's 


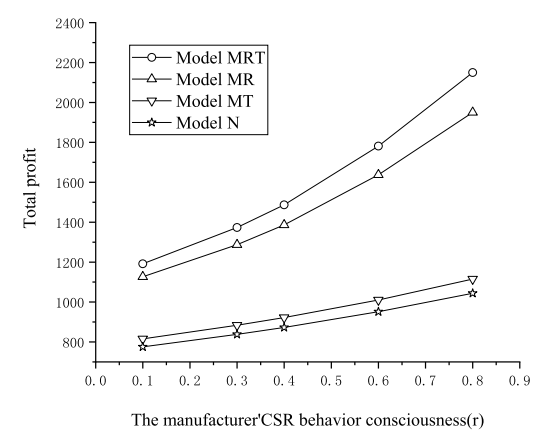

FIGURE 6. Total profits of CSR-CLSC under different levels of CSR behavior consciousness $(\theta=4)$.

CSR behavior consciousness and the retailer's CSR investment, as well as their impact on the manufacturer's cooperative strategy selection and CSR-CLSC operation.

Based on the results of this study, a number of findings and conclusions are presented as follows. (1) The manufacturer's CSR behavior consciousness and the retailer's CSR investment have mutual incentive effects, and they are always conducive to expanding the market demand for new products and improving the recycling rate of waste products. (2) The manufacturer's CSR behavior consciousness will lead to a reduction in her pure profit, but it can bring greater social welfare and help increase the profits of other members and the whole system. (3) The increased sensitivity of consumers to retailer's CSR investment is conducive to expanding the market demand for new products, increasing the recycling rate of waste products, and improving the performance of CSR-CLSC members and whole system. (4) The manufacturer's cooperation strategy is always conducive to reducing the retail price of new products, increasing the CSR investment level, recycling rate of waste products, market demand and consumer surplus. And compared with the cooperation between the manufacturer and third-party, CSR enables the manufacturer and retailer to cooperate more effectively to improve waste product recycling and CSR performance. (5) From the perspective of increasing profits and social welfare, the manufacturer is motivated to cooperate with the retailer or third-party. And compared with cooperation with the third-party, the manufacturer and retailer are more motivated to cooperate, which is also more conducive to lowering the price of new products, increasing the CSR investment level and recycling rate of waste products, and improving the performance of CSR-CLSC members.

Although this study has provided some insights about manufacturer's cooperation strategy and CSR-CLSC operation, several limitations are revealed. Firstly, we mainly consider the situation in which a firm experiences price-and-CSR-dependent deterministic demand. In practice, the market demand of many kinds of products usually exhibits uncertainty. Future research could consider the case of price-and-CSR-dependent random demand. Secondly, we assume that the CSR-CLSC consists of one manufacturer, one retailer and one third-party and do not consider the impact of competition behavior among manufacturers, retailers or third-parties on CSR-CLSC operation, which will be an interesting challenge in future research. Finally, we assume that consumers have the same price perception of new products and remanufactured products, ignoring that consumers still have different price perception of many new products and remanufactured products in reality. Therefore, in the future, we could study the decision-making of CSR-CLSC and the choice of manufacturer's cooperation strategy when consumers have different price perceptions of new products and remanufactured products.

\section{Appendix A.}

Proof of Model N. According to the Game order of CSR-CLSC with dominant manufacturer, the reverse recursive method is used to solve the problem. As well as Savaskan et al. [45], we use the Hessian matrix to check 
the concavity conditions, which points out the determinants of all its principal minors should be alternatively negative and positive.

The Hessian matrix of $\pi_{r}^{\mathrm{N}}(p, d)$ is $\mathrm{H}_{r}=\left(\begin{array}{cc}\frac{\partial \pi_{r}^{2}}{\partial p^{2}} & \frac{\partial \pi_{r}^{2}}{\partial p \partial d} \\ \frac{\partial \pi_{r}^{2}}{\partial d \partial p} & \frac{\partial \pi_{r}^{2}}{\partial d^{2}}\end{array}\right)=\left(\begin{array}{ll}-2 \beta & \theta+\beta \\ \theta+\beta & -2(\theta+g)\end{array}\right)$, it is easy to verify that $\Delta_{r}^{1}=-2 \beta<0, \Delta_{r}^{2}=4 \beta(\theta+g)-(\theta+\beta)^{2}>0$. So, the Hessian matrix $\mathrm{H}_{r}$ of profit function $\pi_{r}^{\mathrm{N}}(p, d)$ is negative definite matrices, and $\pi_{r}^{\mathrm{N}}(p, d)$ is a strictly concave function of $p, d$. And $\pi_{t}^{\mathrm{N}}(\tau)$ is concave in $\tau$ since $\frac{\pi_{t}^{\mathrm{N}}(\tau)^{2}}{\tau^{2}}=-2 k<0$. According to the first order condition, that is, $\frac{\partial \pi_{r}^{\mathrm{N}}}{\partial p}=0, \frac{\partial \pi_{r}^{\mathrm{N}}}{\partial d}=0, \frac{\partial \pi_{t}^{\mathrm{N}}}{\partial \tau}=0$, the best feedback functions of new product's price, CSR investment level, and waste product recycling rate are obtained as: $p^{\mathrm{N}}=\frac{(\theta-\beta)(a-\theta w)+2 g(a+\beta w)}{4 g \beta-(\theta-\beta)^{2}}, d^{\mathrm{N}}=\frac{(\theta-\beta)(a-\beta w)}{4 g \beta-(\theta-\beta)^{2}}, \tau^{\mathrm{N}}=\frac{g \beta(a-\beta w)(b-A)}{k\left(4 g \beta-(\theta-\beta)^{2}\right)}$.

Substituting equations $p^{\mathrm{N}}, d^{\mathrm{N}}, \tau^{\mathrm{N}}$ into equation (4.1), can get the Hessian matrix of $V_{m}{ }^{\mathrm{N}}(w, b)$ is $\mathrm{H}_{m}=$ $\left(\begin{array}{ll}\frac{\partial V_{m}^{2}}{\partial w^{2}} & \frac{\partial V_{m}^{2}}{\partial w \partial b} \\ \frac{\partial V_{m}^{2}}{\partial b \partial w} & \frac{\partial V_{m}^{2}}{\partial b^{2}}\end{array}\right)=\left(\begin{array}{ll}\frac{-4 g \beta^{2}\left(4 k g \beta(1-r)-g \beta^{2}\left(c_{m}-c_{r}-b\right)(b-A)-k(\theta-\beta)^{2}\right)}{k\left(4 g \beta-(\theta-\beta)^{2}\right)^{2}} & \frac{-4 g^{2} \beta^{3}(a-\beta w)\left(c_{m}-c_{r}-2 b+A\right)}{k\left(4 g \beta-(\theta-\beta)^{2}\right)^{2}} \\ \frac{-4 g^{2} \beta^{3}(a-\beta w)\left(c_{m}-c_{r}-2 b+A\right)}{k\left(4 g \beta-(\theta-\beta)^{2}\right)^{2}} & \frac{-4 g^{2} \beta^{2}(a-\beta w)^{2}}{k\left(4 g \beta-(\theta-\beta)^{2}\right)^{2}}\end{array}\right)$, it is easy to verify that $\Delta_{m}^{1}=\frac{-4 g \beta^{2}\left(4 k g \beta(1-r)-g \beta^{2}\left(c_{m}-c_{r}-b\right)(b-A)-k(\theta-\beta)^{2}\right)}{k\left(4 g \beta-(\theta-\beta)^{2}\right)^{2}}<0, \Delta_{m}^{2}=4 k g \beta(1-r)-g \beta^{2}\left(\left(c_{m}-c_{r}-b\right)(b-\right.$ $\left.A)+\left(c_{m}-c_{r}-2 b+A\right)^{2}\right)-k(\theta-\beta)^{2}>0$, so $V_{m}^{\mathrm{N}}(w, b)$ is jointly concave in $w, b$. According to the first order condition, that is, $\frac{\partial V_{m}^{\mathrm{N}}}{\partial w}=0, \frac{\partial V_{m}^{\mathrm{N}}}{\partial b}=0$, the optimal wholesale price $w^{\mathrm{N}^{*}}$ and manufacturer's transfer payment $b^{\mathrm{N}^{*}}$ can be obtained.

By substituting $w^{\mathrm{N}^{*}}$ and $b^{\mathrm{N}^{*}}$ into $p^{\mathrm{N}}, d^{\mathrm{N}}$ and $\tau^{\mathrm{N}}$ respectively, the optimal $p^{\mathrm{N}^{*}}$ and $d^{\mathrm{N}^{*}}$ of the retailer and the optimal $\tau^{\mathrm{N}^{*}}$ of third-party can be obtained, furthermore, the maximum market demand $q^{\mathrm{N}^{*}}$ can be obtained. Finally, by substituting the above equilibrium variables into the profit function of each member enterprise, the pure profits, total profits (Social Welfare) of manufacturer, retailer, third-party and whole CSR-CLSC can be obtained.

Proof of Model MR and Model MT. Similar to the solution method and process in Model N, the reverse recursion method can be used to obtain the relevant equilibrium results under the MR model and MT model, it is omitted here.

Proof of Model MRT. Firstly, under the assumption of scale parameter $k, g$, it is easy to find the total profit function $V_{s}^{\mathrm{MRT}}(p, d, \tau)$ of whole CSR-CLSC is a joint concave function of $p, d$ and $\tau$, according to the first order condition, the optimal $p^{\mathrm{MRT}^{*}}, d^{\mathrm{MRT}^{*}}$ and $\tau^{\mathrm{MRT}^{*}}$ of whole CSR-CLSC can be obtained. Furthermore, the maximum market demand $q^{\mathrm{MRT}^{*}}$ can be obtained. Finally, by substituting the above equilibrium variables into the total profits function of whole CSR-CLSC, the total profits (Social Welfare) of whole CSR-CLSC can be obtained.

Proof of Proposition 5.1. According to the relevant equilibrium results in Table 2, we can obtain

$$
\frac{\partial d^{\mathrm{N}^{*}}}{\partial r}=\frac{8 k^{2} g \beta(\theta-\beta)\left(a-\beta c_{m}\right)}{\Delta_{4}^{2}}>0
$$

Proof of Proposition 5.2. Since the process of proving Proposition 5.2 are similar to that of Proposition 5.1, it is omitted here.

Proof of Proposition 5.3. According to the relevant equilibrium results in Table 2, it is easy to obtain

$$
\frac{\partial \pi_{m}^{\mathrm{N}^{*}}}{\partial r}=\frac{-64 k^{3} g^{3} \beta^{2}\left(a-\beta c_{m}\right)^{2} r}{\Delta_{4}{ }^{3}}<0
$$




$$
\begin{aligned}
\frac{\partial V_{m}^{\mathrm{N}^{*}}}{\partial r} & =\frac{8 k^{2} g^{2} \beta\left(a-\beta c_{m}\right)^{2}}{\Delta_{4}^{2}}>0, \\
\frac{\partial \pi_{\mathrm{r}}^{\mathrm{N}^{*}}}{\partial r} & =\frac{32 k^{3} g^{2} \beta\left(a-\beta c_{m}\right)^{2} \Delta_{8}}{\Delta_{4}{ }^{3}}>0, \\
\frac{\partial \pi_{t}^{\mathrm{N}^{*}}}{\partial r} & =\frac{8 k^{2} g^{3} \beta^{3}\left(a-\beta c_{m}\right)^{2} \Delta_{1}^{2}}{\Delta_{4}{ }^{3}}>0, \\
\frac{\partial V_{s}^{\mathrm{N}^{*}}}{\partial r} & =\frac{32 k^{2} g^{2} \beta\left(a-\beta c_{m}\right)^{2} \Delta_{23}}{\Delta_{4}{ }^{3}}>0,
\end{aligned}
$$

where, let $k\left(g \beta(8-r)-2(\theta-\beta)^{2}\right)=\Delta_{23}$. Under the assumption of scale parameters $k, g>0, \Delta_{23}>0$.

Proof of Proposition 5.4. Taking Proposition 5.4-(1) as an example, according to the relevant equilibrium results in Table 2 , it is easy to obtain

$$
\begin{aligned}
\frac{\partial w^{\mathrm{N}^{*}}}{\partial \theta} & =\frac{-4 k g(\theta-\beta)\left(a-\beta c_{m}\right)\left(4 k r+\beta \Delta_{1}^{2}\right)}{\Delta_{4}{ }^{2}}<0, \\
\frac{\partial \tau^{\mathrm{N}^{*}}}{\partial \theta} & =\frac{8 k g \beta(\theta-\beta)\left(a-\beta c_{m}\right) \Delta_{1}}{\Delta_{4}{ }^{2}}>0, \\
\frac{\partial d^{\mathrm{N}^{*}}}{\partial \theta} & =\frac{2 k\left(a-\beta c_{m}\right) \Delta_{24}}{\Delta_{4}^{2}}>0, \\
\frac{\partial p^{\mathrm{N}^{*}}}{\partial \theta} & =\frac{2 k\left(a-\beta c_{m}\right) \Delta_{25}}{\Delta_{4}^{2}}>0, \\
\frac{\partial q^{\mathrm{N}^{*}}}{\partial \theta} & =\frac{32 k^{2} g \beta(\theta-\beta)\left(a-\beta c_{m}\right)}{\Delta_{4}{ }^{2}}>0
\end{aligned}
$$

where, let $\left(4 k(4-r)-\beta \Delta_{1}{ }^{2}\right)+4 k(\theta-\beta)^{2}=\Delta_{24}, 2 g \theta\left(8 k(2-r)-\beta \Delta_{1}{ }^{2}\right)+g \beta\left(4 k r+\beta \Delta_{1}{ }^{2}\right)+4 k(\theta-\beta)^{2}=\Delta_{25}$. Under the assumption of scale parameters $k, g>0, \Delta_{24}, \Delta_{25}>0$. Since the process of proof in Propositions 5.4(2) and (1) are similar to the above proof, it is omitted here and completed.

Proof of Proposition 5.5. According to the relevant equilibrium results in Table 2, it is easy to obtain

$$
w^{\mathrm{N}^{*}}-w^{\mathrm{MT}^{*}}=\frac{k g \beta\left(a-\beta c_{m}\right) \Delta_{1}^{2} \Delta_{8}}{\Delta_{4} \Delta_{16}}>0 .
$$

Proof of Propositions 5.6 and 5.7. Since the process of proving Propositions 5.6 and 5.7 are similar to that of Proposition 5.5, it is omitted here.

Proof of Proposition 5.8. From the relevant equilibrium results in Table 2, the profits of the manufacturer and retailer cooperative body in Model MR and Model N are subtracted. Obviously,

$$
\begin{aligned}
\lambda_{1}=V_{m}^{\mathrm{MR}^{*}}-V_{m}^{\mathrm{N}^{*}}-\pi_{r}^{\mathrm{N}^{*}} & =\frac{8 k^{3} g\left(a-\beta c_{m}\right)^{2} \Delta_{8}{ }^{2}}{\Delta_{4}^{2} \Delta_{10}}>0, \\
\pi_{t}^{\mathrm{MR}^{*}}-\pi_{t}^{\mathrm{N}^{*}} & =\frac{4 k^{2} g^{2} \beta^{2}\left(a-\beta c_{m}\right)^{2} \Delta_{1}{ }^{2} \Delta_{8} \Delta_{26}}{\Delta_{4}{ }^{2} \Delta_{10}{ }^{2}}>0,
\end{aligned}
$$

and the profits of the manufacturer and third-party cooperative body in Model MT and Model N are subtracted

$$
\lambda_{2}=V_{m}^{\mathrm{MT}^{*}}-V_{m}^{\mathrm{N}^{*}}-\pi_{t}^{\mathrm{N}^{*}}=\frac{2 k^{2} g^{2} \beta^{2}\left(a-\beta c_{m}\right)^{2} \Delta_{1}^{2} \Delta_{27}}{\Delta_{4}{ }^{2} \Delta_{16}}>0,
$$




$$
\begin{gathered}
\pi_{r}^{\mathrm{MT}^{*}}-\pi_{r}^{\mathrm{N}^{*}}=\frac{k^{2} g^{2} \beta^{2}\left(a-\beta c_{m}\right)^{2} \Delta_{1}{ }^{2} \Delta_{8} \Delta_{28}}{\Delta_{4}{ }^{2} \Delta_{16}{ }^{2}}>0, \\
\lambda_{1}-\lambda_{2}=\frac{4 k^{3} g\left(a-\beta c_{m}\right)^{2} \Delta_{27} \Delta_{29} \Delta_{30}}{\Delta_{4}{ }^{2} \Delta_{10} \Delta_{16}}>0,
\end{gathered}
$$

where, let $g \beta\left(4 k(3-r)-\beta \Delta_{1}^{2}\right)-3 k(\theta-\beta)^{2}=\Delta_{26}, g \beta(4-r)-(\theta-\beta)^{2}=\Delta_{27}, g \beta\left(8 k(4-r)-3 \beta \Delta_{1}^{2}\right)-$ $8 k(\theta-\beta)^{2}=\Delta_{28}, g \beta\left(16 k-\beta \Delta_{1}^{2}\right)-4 k(\theta-\beta)^{2}=\Delta_{29}, g \beta\left(8 k-\beta \Delta_{1}^{2}\right)-2 k(\theta-\beta)^{2}=\Delta_{30}$. Under the assumption of scale parameters $k, g>0, \Delta_{26}, \cdots, \Delta_{30}>0$.

Proof of Proposition 5.9. Since the process of proving Proposition 5.9 are similar to that of Proposition 5.8, it is omitted here.

Acknowledgements. This research is supported by the Heilongjiang Philosophy and Social Sciences Research Planning Project (Grant No. 21GLB065), National Nature Science Foundation of China (Grant No. 72174045, 71701056) and Fundamental Research Foundation for Universities of Heilongjiang Province (Grant No. LGYC2018JC056).

\section{REFERENCES}

[1] A. Aguezzoul, Third-party logistics selection problem: a literature review on criteria and methods. Omega 49 (2014) 69-78.

[2] R. Albuquerque, Y. Koskinen and C.D. Zhang, Corporate social responsibility and firm risk: theory and empirical evidence. Manage. Sci. 65 (2019) 4451-4469.

[3] K.M. Amaeshi, O.K. Osuji and P. Nnodim, Corporate social responsibility in supply chains of global brands: a boundary less responsibility? Clarifications, exceptions and implications. J. Bus. Ethics 81 (2008) 223-234.

[4] A. Arya and B. Mittendorf, Supply chain consequences of subsidies for corporate social responsibility. Prod. Oper. Manage. 24 (2015) 1346-1357.

[5] J. Chaowanapong, J. Jongwanich and W. Ijomah, The determinants of remanufacturing practices in developing countries: evidence from Thai industries. J. Cleaner Prod. 170 (2018) 369-378.

[6] J.M. Chen and C.I. Chang, The co-opetitive strategy of a closed-loop supply chain with remanufacturing. Transp. Res. E Logist. Transp. Rev. 48 (2012) 387-400.

[7] T.M. Choi, Y.J. Li and L. Xu, Channel leadership, performance and coordination in closed-loop supply chains. Int. J. Prod. Econ. 146 (2013) 371-380.

[8] C.H. Chuang, C.X. Wang and Y. Zhao, Closed-loop supply chain models for a high-tech product under alternative reverse channel and collection cost structures. Int. J. Prod. Econ. 156 (2014) 108-123.

[9] G.P. De, P.V. Reddy and G. Zaccour, Incentive strategies for an optimal recovery program in a closed-loop supply chain. Eur. J. Oper. Res. 249 (2016) 605-617.

[10] T. Fabian, Supply chain management in an era of social and environment accountability. Sustain. Dev. Int. 2 (2000) 27-30.

[11] G. Ferrer and J.M. Swaminathan, Managing new and differentiated remanufactured products. Eur. J. Oper. Res. 203 (2010) 370-379.

[12] R. Geyer, L.N.V. Wassenhove and A. Atasu, The economics of remanufacturing under limited component durability and finite product life cycles. Manage. Sci. 53 (2007) 88-100.

[13] K. Govindan, H. Soleimani and D. Kannan, Reverse logistics and closed-loop supply chain: a comprehensive review to explore the future. Eur. J. Oper. Res. 240 (2015) 603-626.

[14] I.H. Hong and J.S. Yeh, Modeling closed-loop supply chains in the electronics industry: a retailer collection application. Transp. Res. E Logist. Transp. Rev. 48 (2012) 817-829.

[15] X.P. Hong, L. Xu and P. Du, Joint advertising, pricing and collection decisions in a closed-loop supply chain. Int. J. Prod. Econ. 167 (2015) 12-22.

[16] C.F. Hsueh, Improving corporate social responsibility in a supply chain through a new revenue sharing contract. Int. J. Prod. Econ. 151 (2014) 214-222.

[17] Y.T. Huang, B.R. Zheng and Z.J. Wang, The value of information sharing in a dual-channel closed-loop supply chain. RAIROOper. Res. 55 (2021) 2001-2022.

[18] S.K. Jena and S.P. Sarmah, Price competition and co-operation in a duopoly closed-loop supply chain. Int. J. Prod. Econ. 156 (2014) 346-360.

[19] T. Kim, C.H. Glock and Y. Kwon, A closed-loop supply chain for deteriorating products under stochastic container return times. Omega 43 (2014) 30-40.

[20] J.J. Kong, F. Yang and T.Z. Liu, Socially responsible supply chains with cost learning effects. RAIRO-Oper. Res. 54 (2020) 119-142.

[21] Y. Li, Research on supply chain CSR management based on differential game. J. Cleaner Prod. 268 (2020) 122171. 
[22] J.H. Li and G.Y. Huang, Governance mechanism of supply chain social responsibility, corporate social responsibility and supply chain partnership. Manage. Rev. 31 (2019) 242-254.

[23] J. Li, Z. Wang, B. Jiang and T. Kim, Coordination strategies in a three-echelon reverse supply chain for economic and social benefit. App. Math. Model. 49 (2017) 599-611.

[24] H. Li, C.X. Wang and M. Shang, Pricing, carbon emission reduction, low-carbon promotion and returning decision in a closed-loop supply chain under vertical and horizontal cooperation. Int. J. Environ. Res. Public Health 14 (2017) $1332-1358$.

[25] Y.T. Lin, A.K. Parlaktürk and J.M. Swaminathan, Vertical integration under competition: forward, backward, or no integration? Prod. Oper. Manage. 23 (2014) 19-35.

[26] Y.Z. Liu and T.J. Xiao, Pricing and collection rate decisions and reverse channel choice in a socially responsible supply chain with green consumers. IEEE Trans. Eng. Manage. 99 (2019) 1-13.

[27] Y. Liu, B.T. Quan, J. Li and J.Y.L. Forrest, A supply chain coordination mechanism with cost sharing of corporate social responsibility. Sustainability 10 (2018) 12-27.

[28] Y. Liu, J. Li, B.T. Quan and J.B. Yang, Decision analysis and coordination of two-stage supply chain considering cost information asymmetry of corporate social responsibility. J. Cleaner Prod. 228 (2019) 1073-1087.

[29] W. Liu, D. Qin, N. Shen, J. Zhang, M. Jin, N. Xie, J. Chen and X. Chang, Optimal pricing for a multi-echelon closed loop supply chain with different power structures and product dual differences. J. Cleaner Prod. 257 (2020) 1-31.

[30] S. Liu, F.M. Yao and D.Y. Chen, CSR investment decision and coordination strategy for closed-loop supply chain with two competing retailers. J. Cleaner Prod. 310 (2021) 1-2.

[31] Z. Liu, K.W. Li, J. Tang, B. Gong and J. Huang, Optimal operations of a closed-loop supply chain under a dual regulation. Int. J. Prod. Econ. 233 (2021) 107991.

[32] Z. Liu, X.X. Zheng, D.F. Li, C.N. Liao and J.B. Sheu, A novel cooperative game-based method to coordinate a sustainable supply chain under psychological uncertainty in fairness concerns. Transp. Res. E Logist. Transp. Rev. 147 (2021) 102237.

[33] P. Ma, J. Shang and H. Wang, Enhancing corporate social responsibility: contract design under information asymmetry. Omega 67 (2017) 19-30.

[34] Z.J. Ma, N. Zhang, Y. Dai and S. Hu, Managing channel profits of different cooperative models in closed-loop supply chains. Omega 59 (2016) 251-262.

[35] N.M. Modak, S. Panda, S.S. Sana and M. Basu, Corporate social responsibility, coordination and profit distribution in a dual-channel supply chain. Pac. Sci. Rev. 16 (2015) 235-249.

[36] N.M. Modak, N. Kazemi and L.E. Cárdenas-Barrónc, Investigating structure of a two-echelon closed-loop supply chain using social work donation as a corporate social responsibility practice. Int. J. Prod. Econ. 207 (2019) 19-33.

[37] N.M. Modak, S. Sinha, S. Panda and N. Kazemi, Analyzing a socially responsible closed-loop distribution channel with recycling facility. SN Appl. Sci. 1 (2019) 1189-1203.

[38] C. Mondal and B.C. Giri, Pricing and used product collection strategies in a two period closed-loop supply chain under greening level and effort dependent demand. J. Cleaner Prod. 265 (2020) 121335.

[39] M. Nematollahi, S. Hosseini-Motlagh and J. Heydari, Coordination of social responsibility and order quantity in a two-echelon supply chain: a collaborative decision-making perspective. Int. J. Prod. Econ. 184 (2017) 107-121.

[40] D.B. Ni and K.W. Li, A game-theoretic analysis of social responsibility conduct in two-echelon supply chains. Int. J. Prod. Econ. 138 (2012) 303-313.

[41] D.B. Ni, K.W. Li and X.W. Tang, Social responsibility allocation in two-echelon supply chains: insights from wholesale price contracts. Eur. J. Oper. Res. 207 (2010) 1269-1279.

[42] S. Panda, N.M. Modak, M. Basu and S.K. Goyal, Channel coordination and profit distribution in a social responsible three-layer supply chain. Int. J. Prod. Econ. 168 (2015) 224-233.

[43] S. Panda, N.M. Modak and L.E.Cárdenas-Barrónc, Coordinating a socially responsible closed-loop supply chain with product recycling. Int. J. Prod. Econ. 188 (2017) 11-21.

[44] R.C. Savaskan and L.N.V. Wassenhove, Reverse channel design: the case of competing retailers. Manage. Sci. 52 (2006) 1-14.

[45] R.C. Savaskan, S. Bhattacharya and L.N.V. Wassenhove, Closed-loop supply chain models with product remanufacturing. Manage. Sci. 50 (2004) 239-253.

[46] C.L. Shi, J.J. Nie, T.Y. Wang, et al. The effect of production diseconomies on manufacturer's different cooperative strategies in closed-loop supply chain. J. Ind. Eng. Eng. Manage. 33 (2019) 184-192.

[47] W. Shi, H. Chen, X.M. Zhang and C. Ma, Optimal alliance strategy and its impact in a closed-loop supply chain by considering greenness and service effort. Math. Probl. Eng. 2021 (2021) 6676482.

[48] T. Shu, Q. Liu, S. Chen, S. Wang and K.K. Lai, Pricing decisions of CSR closed-loop supply chains with carbon emission constraints. Sustainability 10 (2018) 1-25.

[49] L.P. Song, Y.L. Yan and F.M. Yao, Closed-loop supply chain models considering government subsidy and corporate social responsibility investment. Sustainability 12 (2020) 1-27.

[50] S. Swami and J. Shah, Channel coordination in green supply chain management: the case of package size and shelf-space allocation. Technol. Oper. Manage. 2 (2011) 50-59.

[51] C.S. Tang, Socially responsible supply chains in emerging markets: some research opportunities. J. Oper. Manage. 57 (2018) $1-10$.

[52] N. Wan and D.J. Hong, The impacts of subsidy policies and transfer pricing policies on the closed-loop supply chain with dual collection channels. J. Cleaner Prod. 224 (2019) 881-891. 
[53] Z. Wang, B.Y. Li, X.D. Zhu, B. Xin and Y. Wang, The impact of donation subsidy of remanufactured products on manufacturer's pricing-production decisions and performances. J. Cleaner Prod. 202 (2018) 892-903.

[54] Y. Wang, Z. Wang, B.Y. Li, Z. Liu, X. Zhu and Q. Wang, Closed-loop supply chain models with product recovery and donation. J. Cleaner Prod. 227 (2019) 861-876.

[55] Y.Y. Wang, M. Su, L. Shen and R. Tang, Decision-making of closed-loop supply chain under corporate social responsibility and fairness concerns. J. Cleaner Prod. 284 (2021) 125373.

[56] J. Wei, K. Govindan, Y.J. Li and J. Zhao, Pricing and collecting decisions in a closed-loop supply chain with symmetric and asymmetric information. Comput. Oper. Res. 54 (2015) 257-265.

[57] J. Wei, W.Y. Chen and G.X. Liu, How manufacturer's integration strategies affect closed-loop supply chain performance. Int. J. Prod. Res. 59 (2021) 4287-4305.

[58] Y. Wu, H. Li, Q. Gou and J. Gu, Supply chain models with corporate social responsibility. Int. J. Prod. Res. 55 (2017) $6732-6759$.

[59] W.W. Wu, Q. Zhang and Z. Liang, Environmentally responsible closed loop supply chain models for joint environmental responsibility investment, recycling and pricing decisions. J. Cleaner Prod. 259 (2020) 120776.

[60] J. Xie, Cooperative strategies for sustainability in a decentralized supply chain with competing suppliers. J. Cleaner Prod. 113 (2016) 807-821.

[61] Y.F. Yang, A.K.W. Lau, P.K.C. Lee and T.C.E. Cheng, The performance implication of corporate social responsibility in matched Chinese small and medium-sized buyers and suppliers. Int. J. Prod. Econ. 230 (2020) 107-119.

[62] X.M. Zhang, Q.W. Li and G.H. Qi, Decision-making of a dual-channel closed-loop supply chain in the context government policy: a dynamic game theory. Discrete Dyn. Nat. Soc. 2020 (2020) 1-19.

[63] X.M. Zhang, Q.W. Li, Z. Liu and C.T. Chang, Optimal pricing and remanufacturing mode in a closed-loop supply chain of WEEE under government fund policy. Comput. Ind. Eng. 151 (2021) 106951.

[64] X.M. Zhang, C.H. Ma, H.R. Chen and G. Qi, Impact of retailer's vertical and horizontal fairness concerns on manufacturer's online channel mode. Discrete Dyn. Nat. Soc. 2021 (2021) 1-12.

[65] X.X. Zheng, Z. Liu, K.W. Li, J. Huang and J. Chen, Cooperative game approaches to coordinating a three-echelon closed-loop supply chain with fairness concerns. Int. J. Prod. Econ. 212 (2019) 92-110.

[66] Y.W. Zhou, J.C. Li and Y.G. Zhong, Cooperative advertising and ordering policies in a two-echelon supply chain with riskaverse agents. Omega 75 (2018) 97-117.

\section{Subscribe to Open (S2O) A fair and sustainable open access model}

This journal is currently published in open access under a Subscribe-to-Open model (S2O). S2O is a transformative model that aims to move subscription journals to open access. Open access is the free, immediate, online availability of research articles combined with the rights to use these articles fully in the digital environment. We are thankful to our subscribers and sponsors for making it possible to publish this journal in open access, free of charge for authors.

\section{Please help to maintain this journal in open access!}

Check that your library subscribes to the journal, or make a personal donation to the S2O programme, by contacting subscribers@edpsciences.org

More information, including a list of sponsors and a financial transparency report, available at: https://www. edpsciences.org/en/maths-s2o-programme 